\title{
Zeólita A sintetizada a partir de rejeitos do processo de beneficiamento de caulim
}

\section{(Zeolite A synthesized from wastes of kaolin improvement process)}

\author{
D. L.Santana ${ }^{1}$, A.C.F.Saraiva ${ }^{2}$, R.F. Neves ${ }^{1}$, D. L. Silva ${ }^{1}$

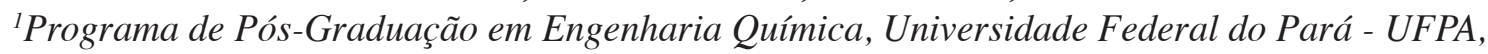 \\ Campus Universitário, Belém, PA 66075-110 \\ ${ }^{2}$ Centro de Tecnologia da Eletronorte, Belém, PA \\ danielaliraeq@yahoo.com.br,dasilva@ufpa.br
}

\begin{abstract}
Resumo
No processo de síntese da zeólita A decidiu-se testar uma matéria-prima alternativa e mais econômica como fonte de sílica e alumínio, pela utilização de rejeitos da indústria do caulim para papel. As zeólitas são substâncias cristalinas com estrutura caracterizada por um arcabouço de tetraedros interligados, cada um consistindo de quatro átomos de oxigênio envolvendo um cátion. O desenvolvimento de processos de síntese de zeólitas desperta um grande interesse para utilização nas áreas de purificação, catálise e adsorção. Os materiais de partida para a síntese da zeólita A constituíram-se de rejeitos de beneficiamento de caulim para papel de empresas do estado do Pará. A zeólita foi obtida após calcinação em 85 e $110{ }^{\circ} \mathrm{C}$ durante $24 \mathrm{~h}$. A caracterização dos materiais de partida foi feita por difração de raios X, análise química, análise térmica gravimétrica e térmica diferencial, e microscopia eletrônica de varredura. A caracterização da zeólita A foi feita por difração de raios X e microscopia eletrônica de varredura. Os rejeitos de caulim utilizados como materiais precursores mostraram ser compostos essencialmente pelo mineral caulinita. Para as temperaturas e tempo empregados na síntese foi possível a formação da fase cristalina da zeólita A, para os dois materiais precursores.
\end{abstract}

Palavras-chave: síntese, caulim, zeólita A.

\begin{abstract}
Raw materials were used to synthesize zeolite A as an alternative and more economical source of silica and aluminum, using waste from the kaolin of the paper industry. Zeolites are crystalline substances with a structure characterized by a framework of linked tetrahedra, each one consisting of four oxygen atoms surrounding a cation. The development of processes for the synthesis of zeolites is of great interest for use in the areas of purification, adsorption and catalysis. The starting materials for the synthesis of zeolite A consisted of wastes from kaolin beneficiation of paper companies of Pará state, Brazil. The zeolite was obtained after calcination at 85 and $110^{\circ} \mathrm{C}$ during $24 \mathrm{~h}$. The chracterization of the starting material was performed by X-ray diffraction, chemical analysis, thermogravimetric and differential thermal analysis, and scanning electron microscopy. The characterization of zeolite A was done by X-ray diffraction and scanning electron microscopy. The kaolin waste used as starting material showed to be essentially kaolinite mineral. For the temperatures and time used in the synthesis it was possible to form the crystalline phase of zeolite Afor the two starting materials.
\end{abstract}

Keywords: synthesis, kaolin, zeolite A.

\section{INTRODUÇÃO}

A indústria extrativa mineral no estado do Pará desempenha um papel importante na economia paraense, tanto no segmento dos minerais metálicos, minério de ferro e minério de cobre, como a dos minerais não metálicos como é o caso do caulim [1]. A região norte do país é detentora das maiores reservas brasileiras de caulim com qualidade de alvura, após beneficiamento, própria para utilização em cobertura de papel, os destaques são para as minas da região do Rio Capim, nordeste do estado do Pará com duas minas importantes em operação e a outra região a do Rio Jarí, com a mina localizada no estado do Amapá com o processo de beneficiamento de caulim realizado no estado do Pará.
Segundo dados declarados das empresas ao DNPM em 2007 a produção de caulim beneficiado foi de 2,53 milhões de tonelada [2]. O processo de beneficiamento de minerais, como vários outros processos industriais, necessita de tratamentos físicos ou físico-químicos com a finalidade de eliminação de impurezas, com isso geram uma quantidade significativa de rejeito, sendo exposto ao meio ambiente de varias maneiras. No processo de beneficiamento de caulim após os devidos tratamentos são gerados dois tipos de rejeitos principais: um que se constitui em um material grosso basicamente sob a forma de quartzo, correspondendo $10 \%$ da produção bruta, que retorna a mina e outro rejeito mais fino formado por uma suspensão aquosa volumosa, constituída essencialmente de caulinita proveniente 
em grande parte das centrífugas, o qual corresponde a aproximadamente $26 \%$ em relação ao caulim processado, que são armazenadas em lagoas de sedimentação [3]. Este tipo de rejeito apresenta ser constituído essencialmente pelo mineral caulim, que é constituído essencialmente pelo argilomineral caulinita, que tem em sua estrutura $\mathrm{Si}$ e Al, com especificações de granulometria e alvura inadequada para utilização em cobertura de papel, tornando-se assim uma fonte alternativa e de baixo custo de matéria prima para a produção de zeólitas [4].

As zeólitas sintéticas são obtidas a partir de soluções aquosas saturadas, de composição definida, sob condições de temperatura $\left(25\right.$ a $\left.300{ }^{\circ} \mathrm{C}\right)$ e pressão pré-determinadas. Sendo assim, fazendo variar a composição da solução (gel de síntese, aluminosilicatos ou metacaulim) e as condições operacionais, é possível obter zeólitas com características estruturais e composições químicas diferentes [5]. Zeólitas são aluminossilicatos hidratados, do grupo dos metais alcalinos e alcalinos terrosos, com arranjo estrutural que apresenta cavidade e canais interconectados nos quais estão presentes íons de compensação como $\mathrm{Na}^{+}, \mathrm{Ca}^{2+}$, $\mathrm{Mg}^{2+}, \mathrm{K}^{+}$e $\mathrm{H}_{2} \mathrm{O}$ [6]. Sua estrutura é caracterizada por um arcabouço de tetraedros interligados, cada um consistindo de quatro átomos de oxigênio envolvendo um cátion. Esse arcabouço contém cavidades abertas, na forma de canais e "gaiolas", normalmente ocupadas por moléculas de água e cátions extra-arcabouço, que são em geral trocáveis. Os canais e os poros são bem definidos possuindo uma elevada área específica, capacidade de troca iônica tornando-se um excelente material adsorvente e catalisador [7]. A capacidade de troca catiônica é a quantidade de íons, particularmente cátions, que este pode adsorver ou trocar, essa importante propriedade é resultado do desequilíbrio das cargas elétricas na estrutura cristalina devido a substituições isomórficas, as ligações químicas quebradas nas áreas das partículas e a interação de íons $\mathrm{H}_{3} \mathrm{O}^{+}$com as cargas nestas ligações quebradas. Para neutralizar, existem cátions trocáveis, que estão fixos eletrostaticamente ao longo das faces e entre as camadas estruturais $[8,9]$. Devido a essa capacidade de troca iônica as zeólitas têm sido amplamente utilizadas no tratamento de efluentes industriais e domésticos, água de abastecimento, água subterrânea, drenagem ácida de minerações e solos contaminados, cabe também ressaltar seu uso na indústria da construção civil [10]. Nesse sentido o Grupo de Processos Inorgânicos da Faculdade de Engenharia Química em parceria com o Grupo de Mineralogia e Geoquímica Aplicada da Universidade Federal do Pará vem desenvolvendo estudos visando à utilização desse tipo de rejeito como fonte de matéria-prima em trabalhos como, por exemplo, síntese de zeólita [11] e também propiciando de maneira técnica um possível destino para o rejeito gerado pelas empresas da região.

A finalidade deste trabalho é a avaliação da possibilidade de se utilizar rejeitos de beneficiamento de caulim como fontes de sílica e alumínio para produção de zeólita A, a fim de disponibilizar uma viabilidade técnica para redução do armazenamento desse rejeito, por meio da sua transformação de baixo valor comercial em um material com alto valor agregado como a zeólita A. Também é objetivo a comparação entre os materiais utilizados na síntese e estudar o efeito da temperatura de reação de síntese sobre a cristalinidade e morfologia do material zeolítico sintetizado.

\section{EXPERIMENTAL}

Como matéria-prima para a produção do adsorvente, zeólita A, foram utilizados rejeitos de caulim de duas regiões diferentes do estado do Pará, uma da região do Rio Capim e a outra da região do Rio Jari em Monte Dourado, ambos oriundos de rejeitos de centrífugas do processo de beneficiamento do caulim para cobertura de papel, como fonte de alumínio e silício. A fonte do metal alcalino necessário para a formação da zeólita $\mathrm{A}$ foi hidróxido de sódio.

Para a produção da zeólita $\mathrm{A}$ foi necessário promover um pré-tratamento da matéria-prima, sendo feita uma ativação térmica submetendo os rejeitos de caulins a uma calcinação em mufla a $700{ }^{\circ} \mathrm{C} / 2 \mathrm{~h}$, para promover a desidroxilação da caulinita com a liberação de água sob a forma de vapor, obtendo-se assim o metacaulim [11]. O método de síntese da zeólita adotado constitui-se em um processo hidrotermal em autoclave estática, onde ocorreu a mistura reacional entre o metacaulim, cerca de $10 \mathrm{~g}$, e a solução de hidróxido de sódio $5 \mathrm{M}$. As temperaturas utilizadas para que ocorresse a cristalização da zeólita A foram 85 e $110{ }^{\circ} \mathrm{C}$ por $24 \mathrm{~h}$, com pressão estimada de $618 \mathrm{kPa}$. Os metacaulins obtidos foram denominados MCC e MCI, que correspondem ao metacaulim da região do rio Jarí e o metacaulim da região do rio Capim, seguidos dos dígitos 700 que caracterizam a temperatura e do digito 2, que corresponde ao tempo. Os materiais sintetizados foram denominados ZC para zeólita A do rio Jarí e ZI para zeólita $\mathrm{A}$ do rio Capim, seguido dos dígitos 85 e 110, que caracterizam as temperaturas 85 e $110{ }^{\circ} \mathrm{C}$, mais o dígito 24 que corresponde o tempo de reação em horas. As Tabelas I e II apresentam as nomenclaturas utilizadas.

Tabela I - Nomenclatura para a região do Rio Jarí. [Table I - Nomenclature for the Jari River region.]

\begin{tabular}{cccc}
\hline Código & Nome & $\begin{array}{c}\text { Temperatura } \\
\left({ }^{\circ} \mathrm{C}\right)\end{array}$ & $\begin{array}{c}\text { Tempo } \\
(\mathrm{h})\end{array}$ \\
\hline MCC7002 & Metacaulim & 700 & 2 \\
ZC8524 & Zeólita A & 85 & 24 \\
ZC11024 & Zeólita A & 110 & 24 \\
\hline
\end{tabular}

Tabela II - Nomenclatura para a região do Rio Capim. [Table II - Nomenclature for the Capim River region.]

\begin{tabular}{cccc}
\hline Código & Nome & $\begin{array}{c}\text { Temperatura } \\
\left({ }^{\circ} \mathrm{C}\right)\end{array}$ & $\begin{array}{c}\text { tempo } \\
(\mathrm{h})\end{array}$ \\
\hline MCI7002 & Metacaulim & 700 & 2 \\
ZI8524 & Zeólita A & 85 & 24 \\
ZI11024 & Zeólita A & 110 & 24 \\
\hline
\end{tabular}


A caracterização dos materiais de partida foi feita por análise química, difração de raios X (DRX), análise térmica (ATD-TG) e microscopia eletrônica de varredura (MEV). Os materiais sintetizados foram caracterizados por DRX e MEV. A análise química foi feita no programa IQ+ Semiquant, por fluorescência de raios $\mathrm{X}$ em disco de vidro para elementos maiores e traços, com o espectrômetro seqüencial Axios Minerals, tubo de raios X de Rh de 2,4 kW, PANalytical. A aquisição de dados foi feita com o programa Super $Q$ Manager, e o tratamento dos dados com o programa $I Q+$, PANalytical. Na preparação do disco de vidro foi utilizado 1 $\mathrm{g}$ da amostra, para $8 \mathrm{~g}$ do fundente tetraborato de lítio.

Para a obtenção dos difratogramas de raios $\mathrm{X}$ foi utilizado o método do pó, em um difratômetro de raios X X`Pert Pro Mpd, PANalytical, com goniômetro PW3050/60 (Teta/ Teta), anodo de cobre $\left(k \alpha_{1}=1,540598 \AA\right), P W 3373 / 00,40$ $\mathrm{kV}$ e $40 \mathrm{~mA}$. O detector foi RTMS X Celerator. A aquisição dos dados foi feita com o programa X' Pert Data Collector, e o tratamento dos dados com o programa X'Pert HighScore .

A análise térmica foi obtida por meio das curvas de decomposição térmica dos materiais no equipamento PL Thermal Sciences com analisador térmico simultâneo STA 1000/1500, Stanton Redcroft Ltd., cadinho de alumina, na faixa da temperatura ambiente até $1000^{\circ} \mathrm{C}$, com taxa $10^{\circ} \mathrm{C} / \mathrm{mim}$.

As análises morfológicas da estrutura cristalina dos materiais foram feitas em microscópio eletrônico de varredura Leo-1430. As condições de análise para as imagens de elétrons secundários foram: corrente de feixe de elétrons $90 \mu \mathrm{A}$, voltagem $10 \mathrm{kV}$, distância de trabalho 15-12 $\mathrm{mm}$. As amostras foram preparadas com uma fina camada de ouro usando um metalizador Emitech K550.

\section{RESULTADOS E DISCUSSÃO}

Na Tabela III estão apresentados os resultados de análise química dos materiais de partida, rejeitos de caulim, (RCC e

Tabela III - Análise química dos rejeitos de caulim.

[Table III - Chemical analysis of the kaolin wastes.]

\begin{tabular}{cccc}
\hline Compostos $(\%)$ & $\mathrm{RCC}$ & $\mathrm{RCI}$ & $\begin{array}{c}\text { Valor } \\
\text { Teórico }\end{array}$ \\
\hline $\mathrm{SiO}_{2}$ & 45,585 & 46,714 & 46,54 \\
$\mathrm{Al}_{2} \mathrm{O}_{3}$ & 36,545 & 37,995 & 39,50 \\
$\mathrm{Fe}_{2} \mathrm{O}_{3}$ & 1,871 & 0,530 & - \\
$\mathrm{TiO}_{2}$ & 1,005 & 0,273 & - \\
$\mathrm{CaO}$ & 0,00 & 0,024 & - \\
$\mathrm{BaO}$ & 0,00 & 0,155 & - \\
$\mathrm{Na}_{2} \mathrm{O}$ & 0,354 & 0,227 & - \\
$\mathrm{K}_{2} \mathrm{O}$ & 0,00 & 0,069 & - \\
$\mathrm{ZrO}_{2}$ & & 0,013 & \\
$\mathrm{P}_{2} \mathrm{O}_{5}$ & & 0,020 & \\
$\mathrm{PF}^{*}$ & 14,31 & 13,98 & 13,96 \\
$\mathrm{Total}^{*}$ & 99,67 & 100 & 100,00 \\
\hline
\end{tabular}

*Perda ao Fogo
RCI) e os valores de caulinita teórica para a comparação. Os valores para $\mathrm{SiO}_{2} \mathrm{e} \mathrm{Al}_{2} \mathrm{O}_{3}$ são os componentes principais dos rejeitos, correspondendo a $82,1 \%$ para RCC-700 e $84,7 \%$ para RCI-700. Os outros componentes apresentam uma pequena porcentagem para ambos os materiais, os valores de $\mathrm{Fe}_{2} \mathrm{O}_{3}(1,9 \%)$ e $\mathrm{TiO}_{2}(1,0 \%)$ para $\mathrm{RCC}$ e os valores de $\mathrm{Fe}_{2} \mathrm{O}_{3}(0,5 \%)$ e $\mathrm{TiO}_{2}(0,3 \%)$ para $\mathrm{RCI}$, o que indica que $\mathrm{RCI}$ é mais puro do que RCC. Os materiais possuem perda ao fogo $\left(\mathrm{H}_{2} \mathrm{O}\right) 14,8$ para $\mathrm{RCC}$ e 14,0 para RCI, revelando que RCI está mais próximo do valor teórico da caulinita que é $13,96 \%$ [12]. As amostras apresentaram valores coerentes no que diz respeito à quantidade de óxido de silício e óxido de alumínio, quando comparadas com os parâmetros teóricos.

Por meio das análises dos difratogramas das amostras dos materiais precursores (Figs. 1 e 2), foi identificado o argilomineral caulinita como principal constituinte, mostrando que a sílica quantificada pela análise química corresponde à presente na caulinita, confirmando que os

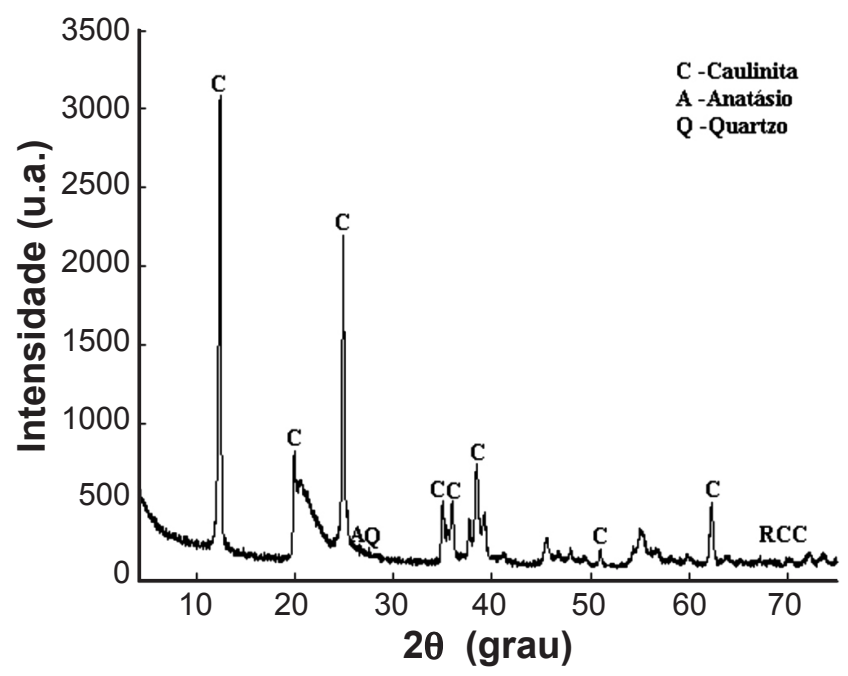

Figura 1: Difratograma de raios X do material RCC.

[Figure 1: X-ray diffraction pattern of RCC material.]

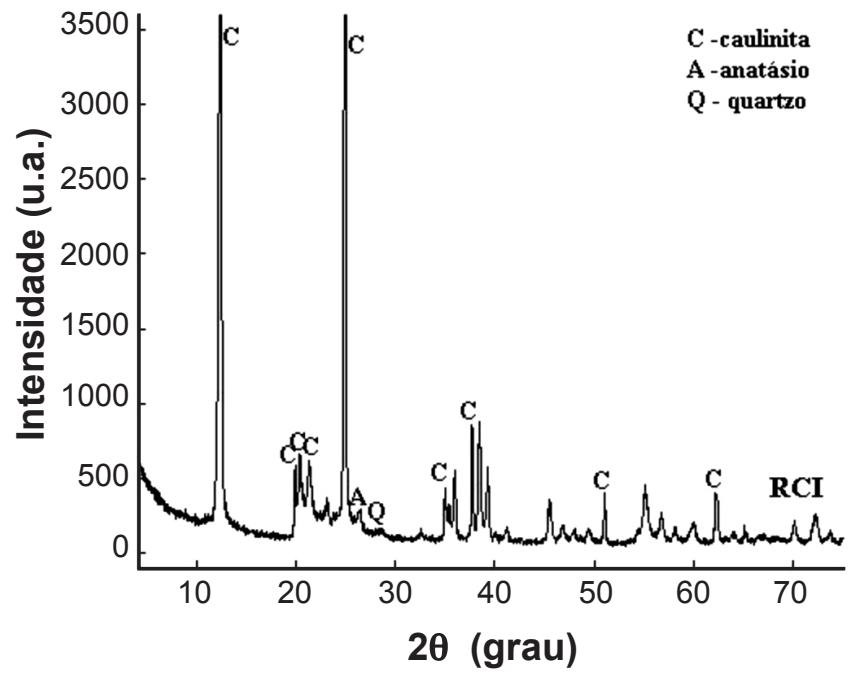

Figura 2: Difratograma de raios X do material RCI. [Figure 2: X-ray diffraction pattern of RCI material.] 


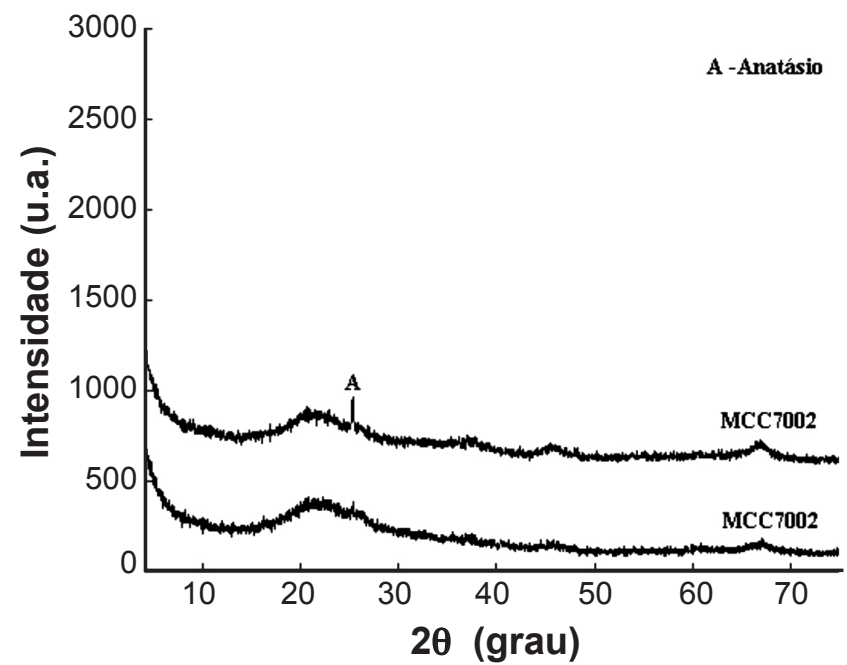

Figura 3: Difratogramas de raios X dos metacaulins MCI7002 e MCC7002 dos rejeitos das regiões do Rio Capim, PA, e do Rio Jarí, PA, respectivamente.

[Figure 3: X-ray diffraction pattern of metakaolin wastes MCI7002 and MCC7002 from Capim River, PA, and Jari River, PA, Brazil, respectively.]
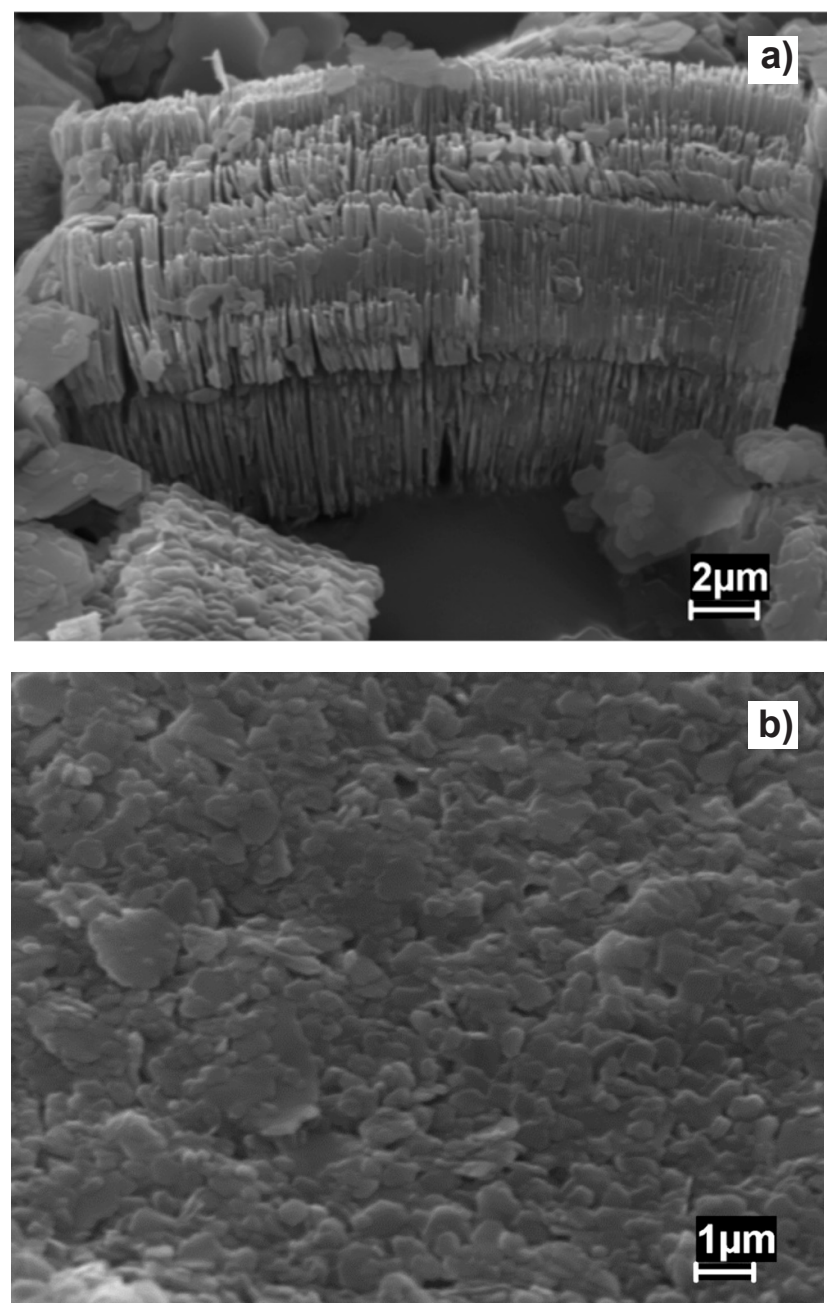

Figura 4: Micrografias MEV dos rejeitos cauliníticos RCI (a) e RCC (b).

[Figure 4: SEM micrographs of kaolinitics wastes RCI (a) and $R C C(b)$.] materiais são compostos essencialmente por sílica e alumina, alvos de interesse. Na Fig. 3 são apresentados os materiais calcinados a $700{ }^{\circ} \mathrm{C}$ por $2 \mathrm{~h}$ onde se observa a quebra total da
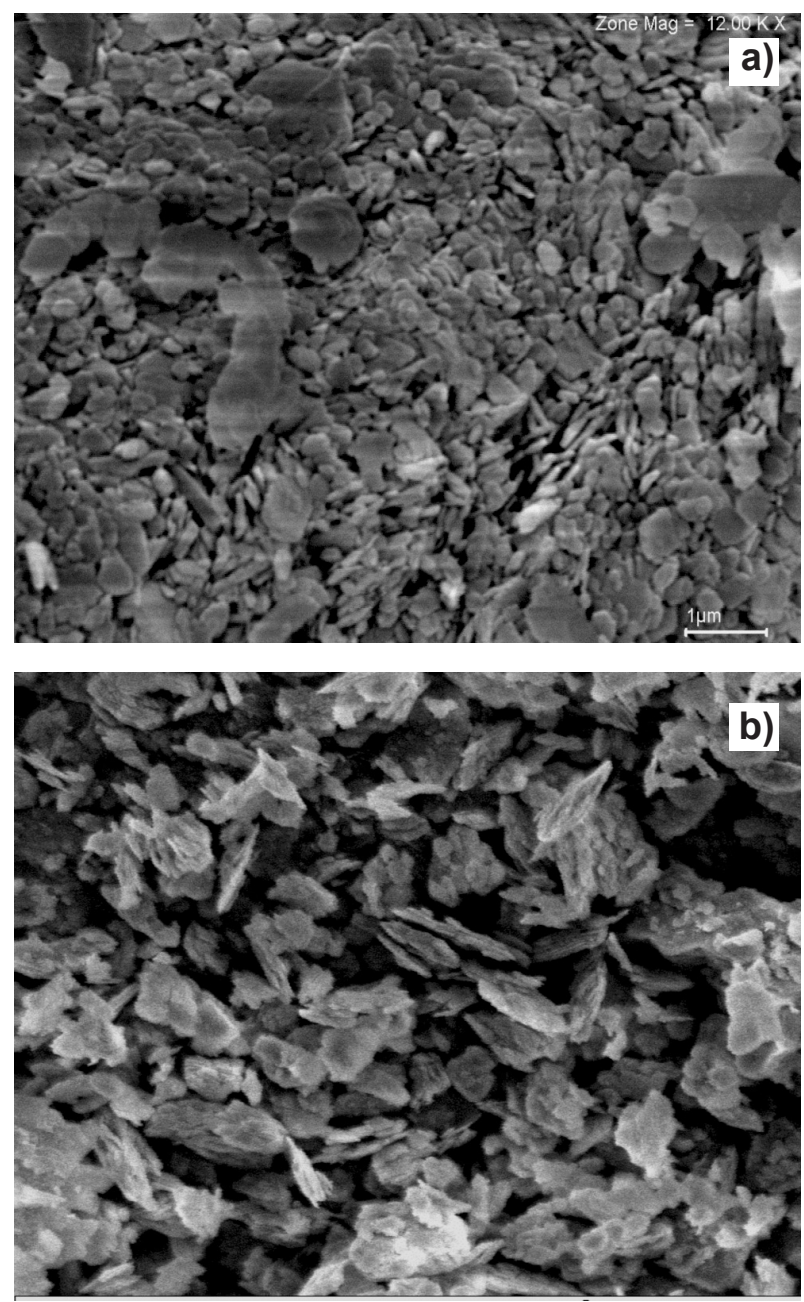

Figura 5: Micrografias MEV dos materiais calcinados MCI7002 (a) e MCC7002 (b).

[Figure 5: Micrographs of calcined materials MCI7002 (a) and MCC7002 (b).]

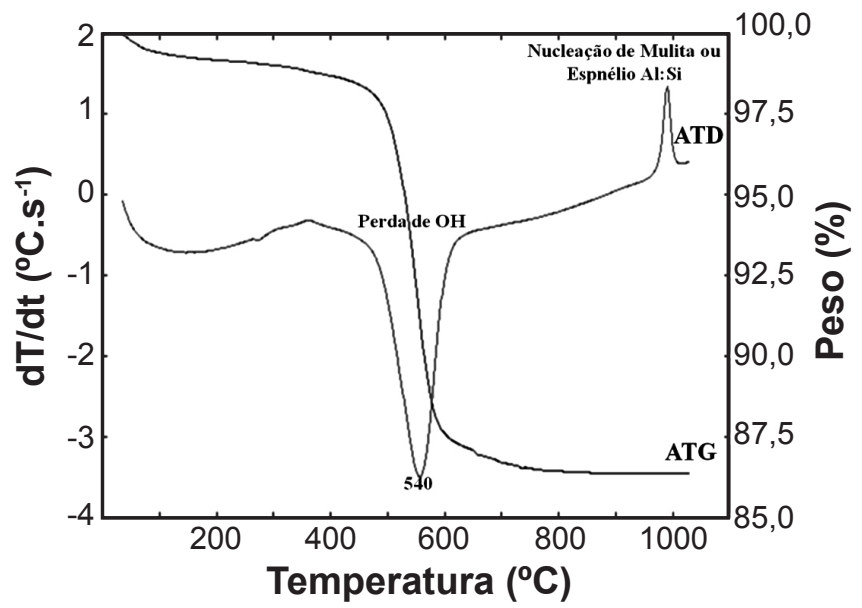

Figura 6: Curvas de análise termogravimétrica e térmica diferencial do material RCC.

[Figure 6: TG and DTA curves of RCC material.] 


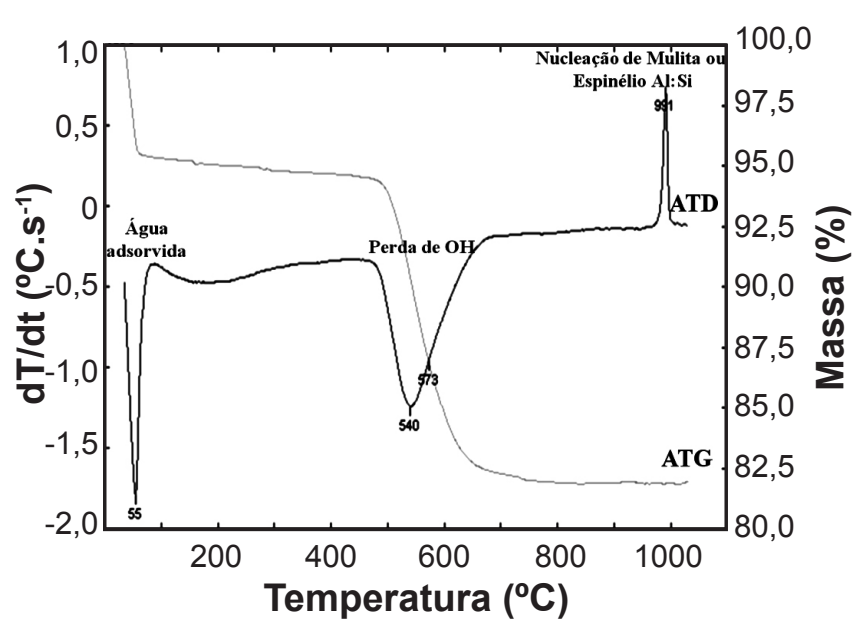

Figura 7: Curvas de análise termogravimétrica e térmica diferencial do material RCI.

[Figure 7: TG and DTA curves of RCI material.]

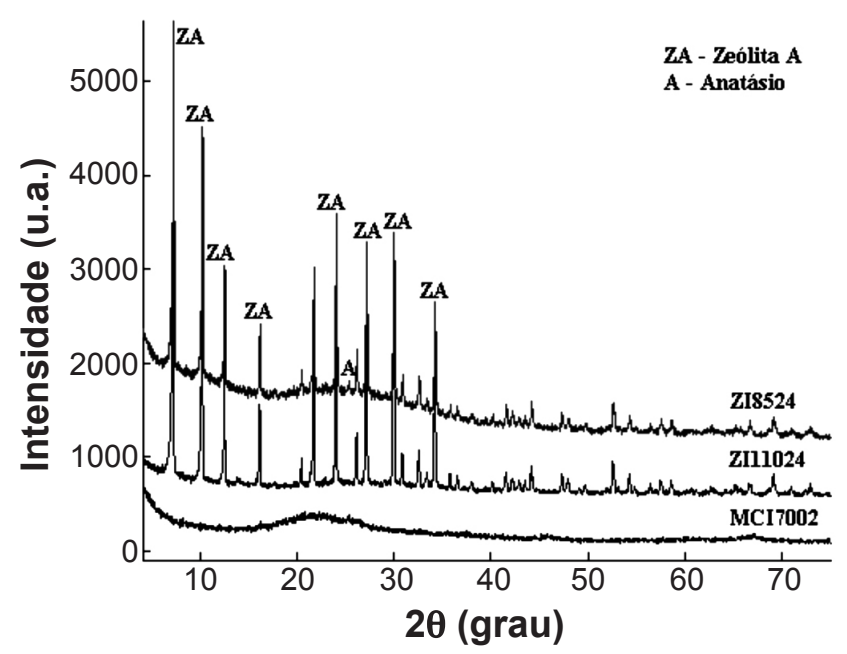

Figura 8: Difratogramas de raios $\mathrm{X}$ do metacaulim e dos materiais sintetizados da região do Rio Capim.

[Figure 8: X-ray diffraction patterns of metakaolin and synthetized materials from Capim River region.]

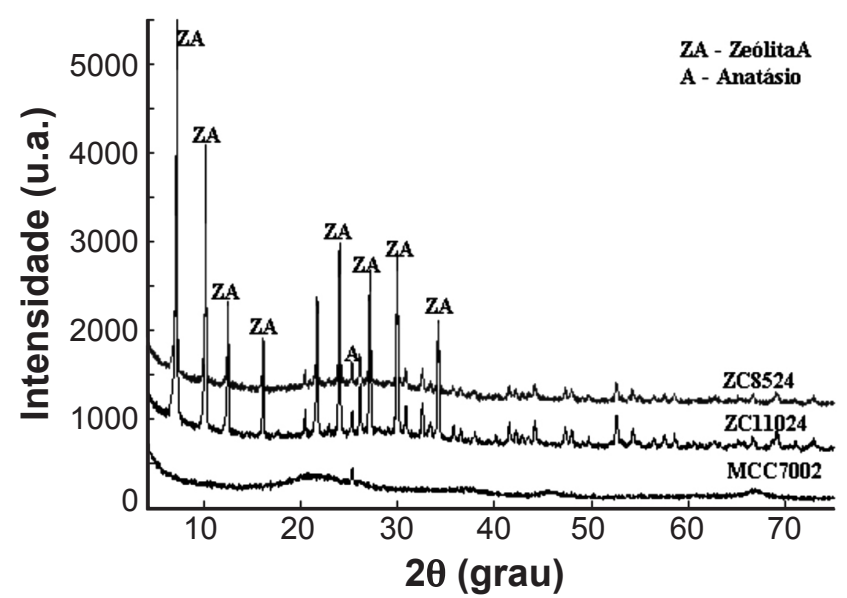

Figura 9: Difratogramas de raios X do metacaulim e dos materiais sintetizados da região do Rio Jarí.

[Figure 9: X-ray diffraction patterns of metakaolin and synthetized materials from Jari River region.]
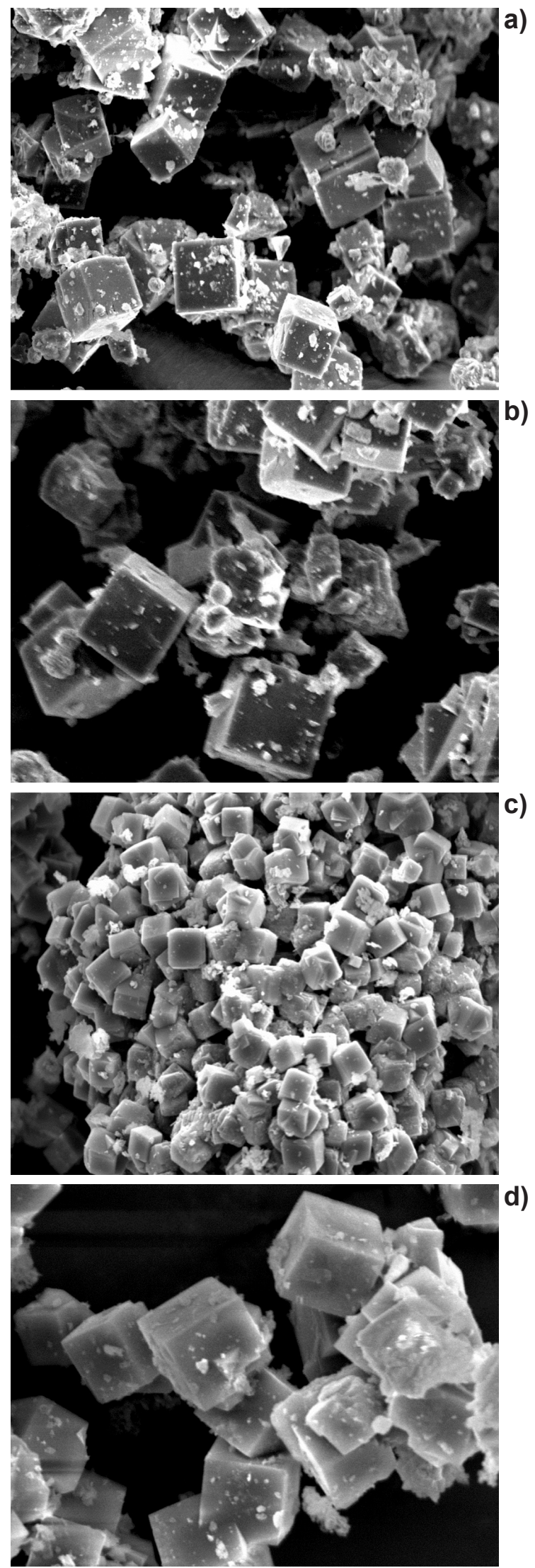

Figura 10: Micrografias MEV dos materiais sintetizados ZI8524 (a), ZI11024 (b), ZC8524 (c) e ZC11024 (d).

[Figure 10: Micrographs of the synthesized materials ZI8524 (a), ZI11024 (b), ZC8524 (c) and ZC11024 (d).] 
estrutura cristalina da caulinita, devido à sua desidroxilação.

$\mathrm{Na}$ Fig. 4 são mostradas as micrografias obtidas em microscópio eletrônico de varredura dos materiais precursores. A morfologia é característica da caulinita em ambos os materiais, formada por cristais pseudo-hexagonais na forma de pilastras (booklets) (Fig. 4a) e cristais na forma de lamelas (Fig. 4b). As micrografias geradas dos precursores calcinados a $700{ }^{\circ} \mathrm{C}$ por $2 \mathrm{~h}$, metacaulinita, (MCC7002 e MCI7002) mostram que a forma pseudo-hexagonal e lamelar permanece. Essas formas estão como aglomerados de partículas, Figs. 5a e 5b, para ambos os materiais [13, 14].

Nas Figs. 6 e 7 estão as curvas das análises termogravimétrica e térmica diferencial dos rejeitos de caulim RCC e RCI. Na análise térmica diferencial dos dois materiais, em $\sim 540{ }^{\circ} \mathrm{C}$ há uma banda endotérmica, que se inicia em $450{ }^{\circ} \mathrm{C}$ e se completa em $\sim 600^{\circ} \mathrm{C}$, que corresponde à desidroxilação da caulinita. Também pode ser observado que em torno de $990{ }^{\circ} \mathrm{C}$ ocorre a formação de um pico que corresponde a formação de espinélio $\mathrm{Al}: \mathrm{Si}$ ou mulita [13]. Nas mesmas figuras têm-se as curvas termogravimétricas, com uma perda de massa de $\sim 13,9 \%$, resultado próximo da perda de massa teórica da caulinita $(13,96 \%)$ [12].

Nas Figs. 8 e 9 são apresentados os resultados da difração de raios $\mathrm{X}$ dos metacaulins obtidos e os dos materiais sintetizados a 85 e $110{ }^{\circ} \mathrm{C}$ de reação por $2 \mathrm{~h}$. Houve a formação da fase cristalina, característica da zeólita $\mathrm{A}$ para os dois precursores em estudo, tanto a $110{ }^{\circ} \mathrm{C}$, quanto a $85^{\circ} \mathrm{C}$.

As micrografias dos materiais sintetizados revelam que houve a formação de cristais cúbicos, típicos de morfologia de zeólita $\mathrm{A}$, para os dois materiais, tanto a $110{ }^{\circ} \mathrm{C}$ quanto a $85{ }^{\circ} \mathrm{C}$, Figs. 10a e 10 b para ZI8524 e ZI11024, respectivamente; e nas Figs. 10c e 10d para ZC8524 e ZC11024, respectivamente.

\section{CONCLUSÕES}

Os rejeitos de caulim utilizados como material precursor são compostos essencialmente pelo mineral caulinita, que é constituído pelos elementos $\mathrm{Si}$ e Al, mostrando serem fontes em potencial para o processo de síntese de zeólitas. Foi possível a obtenção da zeólita A com a utilização dos rejeitos como fonte de Si e Al, conforme análise de difração de raios $\mathrm{X}$ e microscopia eletrônica de varredura, e com a utilização de $\mathrm{NaOH}$ como solução fornecedora do metal necessário, mostrando serem tecnicamente viáveis nas condições aplicadas. Para as temperaturas de sínteses estudadas, 85 e $110{ }^{\circ} \mathrm{C}$ durante $24 \mathrm{~h}$, foi possível a formação da fase cristalina da zeólita A para os dois materiais precursores.
Comparando-se os dois materiais no processo de síntese da zeólita A, tanto ZI2485 quanto ZC2485 que foi obtido a $85^{\circ} \mathrm{C}$, ocorreu a cristalização da zeólita $\mathrm{A}$, havendo apenas variações nas intensidades dos picos para essa temperatura, fato esse que se repetiu para os materiais a $110^{\circ} \mathrm{C}$.

\section{REFERÊNCIAS}

[1] R. A. C. Mártires, A. L. Santana Informe Mineral Pará 2008/2007, Departamento Nacional de Produção Mineral DNPM (2008).

[2] R. A. C. Mártires, G. L. S. Sena, Sumário Mineral, Departamento Nacional de Produção Mineral - DNPM (2008).

[3] A. A. B. Maia, R. S. Angélica, R. F. Neves, Estabilidade térmica da zeólita A sintetizada a partir de um rejeito da Amazônia, Cerâmica 54 (2008) 345.

[4] D. L. Santana, E. M. O. Moraes, M. C. Martelli, R. F. Neves, Anais Cong. Bras. Eng. Quim., Recife, PE (2008).

[5] A. B. Luz, Zeólitas: Propriedades e usos industriais, Série Tecnologia Mineral 68, Centro de Tecnologia Mineral - CETEM (1994).

[6] D. W. Breck, Zeolitic molecular sieves: structure, chemistry and use, Wiley, N. York, EUA (1974).

[7] M. B. M. Monte, N. G. A. M. Resende, Zeólitas Naturais, Centro de Tecnologia Mineral - CETEM (2005).

[8] M. R. Aguiar, A. C. Novaes, Química Nova 25, 6B (2002) 1145 .

[9] L. A. Mendonça, Estudo de viabilidade técnica de recuperação de metais a partir de Zeólitas comerciais desativadas, Diss. Mestrado, Universidade Federal do Rio de Janeiro, COPPE, Rio de Janeiro, RJ (2005).

[10] M. C. Shinzato, Rev. Inst. Geológico 27-28 ( 2007) 65. [11] A. A. B. Maia, Síntese da zeólita A utilizando como precursor um rejeito de beneficiamento de caulim da Amazônia: aplicação como adsorvente, Diss. Mestrado Eng. Quim., Universidade Federal do Pará, Belém, PA (2007).

[12] H. H. Murray, Applied Clay Mineralogy: Occurrences, processing and application of kaolins, bentonites, palygorskite-sepiolite, and common clays, $1^{\text {st }}$ Ed., Elsevier, Amsterdam, Holanda (2007) 9.

[13] P. S. Santos, Ciência e Tecnologia das Argilas, vol. 1, Edgard Blucher Ltda., S. Paulo, SP (1992)

[14] M. C. Martelli, Transformações Térmicas e Propriedades Cerâmicas de Resíduos de Caulins das Regiões do Rio Capim e do Rio Jarí-Brasil, Tese Dr., Geoquímica e Petrologia, Centro de Geociências, Universidade Federal do Pará, Belém, PA (2006).

(Rec. 11/02/2011, Ac. 10/06/2011) 